Review

\title{
Regulation of cell-to-cell communication mediated by astrocytic ATP in the CNS
}

\author{
Schuichi Koizumi ${ }^{1}$, Kayoko Fujishita ${ }^{1,2} \&$ Kazuhide Inoue ${ }^{2,3}$ \\ ${ }^{1}$ Division of Pharmacology, National Institute of Health Sciences, Kamiyoga, Setagaya, Tokyo, Japan; ${ }^{2}$ Division of \\ Biosignaling, National Institute of Health Sciences, Kamiyoga, Setagaya, Tokyo, Japan; ${ }^{3}$ Department of Molecular and \\ System Pharmacology, Graduate School of Pharmaceutical Sciences, Kyushu University, Maidashi, Higashi, Fukuoka, \\ Japan
}

Received 29 November 2004; accepted in revised form 25 February 2005

Key words: ATP, astrocytes, glia-to-neuron communication, gliotransmitter, hippocampus, P2Y1 receptor, tripartite synapse

\begin{abstract}
It has become apparent that glial cells, especially astrocytes, not merely supportive but are integrative, being able to receive inputs, assimilate information and send instructive chemical signals to other neighboring cells including neurons. At first, the excitatory neurotransmitter glutamate was found to be a major extracellular messenger that mediates these communications because it can be released from astrocytes in a $\mathrm{Ca}^{2+}$-dependent manner, diffused, and can stimulate extra-synaptic glutamate receptors in adjacent neurons, leading to a dynamic modification of synaptic transmission. However, recently extracellular ATP has come into the limelight as an important extracellular messenger for these communications. Astrocytes express various neurotransmitter receptors including P2 receptors, release ATP in response to various stimuli and respond to extracellular ATP to cause various physiological responses. The intercellular communication " $\mathrm{Ca}^{2+}$ wave" in astrocytes was found to be mainly mediated by the release of ATP and the activation of P2 receptors, suggesting that ATP is a dominant "gliotransmitter" between astrocytes. Because neurons also express various P2 receptors and synapses are surrounded by astrocytes, astrocytic ATP could affect neuronal activities and even dynamically regulate synaptic transmission in adjacent neurons as if forming a "tripartite synapse". In this review, we summarize the role of astrocytic ATP, as compared with glutamate, in gliotransmission and synaptic transmission in neighboring cells, mainly focusing on the hippocampus. Dynamic communication between astrocytes and neurons mediated by ATP would be a key event in the processing or integration of information in the CNS.
\end{abstract}

Abbreviations: $\left[\mathrm{Ca}^{2+}\right] \mathrm{i}$ - intracellular $\mathrm{Ca}^{2+}$ concentration; CFTR - cystic fibrosis transmembrane conductance regulator; $\mathrm{CNS}$ - central nervous system; $\mathrm{InsP}_{3}$ - inositol 1,4,5-trisphosphate; SNARE-soluble $N$-ethylmaleimide-sensitive fusion protein (NSF) attachment protein receptor

\section{Introduction}

In the mid-19th century, Rudolph Virchow, a German anatomist, first found non-neuronal cells in the central nervous system (CNS) and called them "glia", a Greek for "glue". The name reflects the original view that glia played merely a structural or supportive role for neurons. They occupy over $70 \%$ of the total cell population in the CNS and are classified into microglia, oligodendrocytes and astrocytes. Now it has become apparent that glia, especially astrocytes, are much more than "glue" but rather are integrative, being able to receive inputs, to assimilate

Correspondence to: Dr Schuichi Koizumi, PhD, Division of Pharmacology, National Institute of Health Sciences, 1-18-1 Kamiyoga, Setagaya, Tokyo, 158-8501, Japan. Tel: +81-3-3700-9698; Fax: +81-3-3700-9698; E-mail: skoizumi@nihs.go.jp information and to send instructive chemical signals both to neurons and to other neighboring cells. Although rapid neurotransmission was believed to be restricted solely to neuron-to-neuron communication, it has been found to include glial cells $[1,2]$. The first evidence for dynamic communication from astrocytes to neurons came from the discovery of temporally related changes in the intracellular $\mathrm{Ca}^{2+}$ concentration $\left(\left[\mathrm{Ca}^{2+}\right] \mathrm{i}\right)$ in glial and neuronal cells. Various stimuli which selectively elevate $\left[\mathrm{Ca}^{2+}\right] \mathrm{i}$ in astrocytes lead to delayed elevations in $\left[\mathrm{Ca}^{2+}\right] \mathrm{i}$ in neurons in culture [3]. In hippocampal slice preparations, activation of metabotropic glutamate receptors in astrocytes evokes $\mathrm{Ca}^{2+}$ signals in astrocytes, which are followed by a delayed elevation of neuronal $\mathrm{Ca}^{2+}$ levels $[4,5]$. Evidence suggests that such $\mathrm{Ca}^{2+}$-mediated extracellular signaling between astrocytes and neurons may be involved in the regulation of synaptic transmission. Stimulation of $\mathrm{Ca}^{2+}$ waves in 
astrocytes can increase both excitatory and inhibitory postsynaptic currents in hippocampal cultures [6]. In the retina, astrocytic $\mathrm{Ca}^{2+}$ waves can modulate the light-induced excitation of ganglion cells [7]. Glutamate appears to be an important mediator for these astrocyte-to-neuron signals.

There is an increasing body of evidence however, that ATP, the predominant extracellular signaling molecule among astrocytes [8-12], may also mediate signaling between neurons and glial cells [13]. Neurons are known to express a wide variety of ionotropic (P2X) and metabotropic (P2Y) receptor subtypes in the pre- and postsynaptic regions, and ATP could directly mediate synaptic transmission as a fast neurotransmitter in the rat medial habenula [14] and in the spinal cord dorsal horn [15]. In addition, exogenously applied ATP potentiates [16-19] or inhibits $[20,21]$ synaptic transmission in the CNS. Given that astrocytic $\mathrm{Ca}^{2+}$ waves can evoke changes in neuronal synaptic activity and that $\mathrm{Ca}^{2+}$ waves are mediated by the release of ATP, ATP released from astrocytes may be involved in astrocyte-to-neuron signaling in synaptic regions of the CNS.

In this review, we summarize the role of astrocytic ATP, as compared with glutamate, in gliotransmission and synaptic transmission in neighboring cells, mainly focusing on the hippocampus. This finding of a novel ATP-mediated signaling system between astrocytes and neurons complements a growing body of evidence, suggesting that, in addition to their various supportive roles for neurons, astrocytes are actively involved in the control of synaptic transmission.

\section{Astrocyte-to-astrocyte communication " $\mathrm{Ca}^{2+}$ wave"}

The development of video imaging techniques allowed the observation that neurotransmitters elicit increases in $\left[\mathrm{Ca}^{2+}\right] \mathrm{i}$ even in glial cells. Since unlike neurons, astrocytes do not produce action potentials, they were thought to be quiet. However, they have rather found to be busy or noisy in terms of " $\mathrm{Ca}^{2+}$ excitability". About 15 years ago, elevations in $\left[\mathrm{Ca}^{2+}\right] \mathrm{i}$ in individual cultured astrocytes in response to neurotransmitters were first reported [22-24]. After initial observations demonstrated the presence of $\mathrm{Ca}^{2+}$ excitability within astrocytes, it became apparent that many neurotransmitters stimulate $\mathrm{Ca}^{2+}$ elevations in glial cells by activating specific receptors expressed on these cells. Astrocytes express metabotropic glutamate receptors [3], dopamine receptors [25, 26], noradrenaline receptors [27], serotonin receptors [28-31] and $\mathrm{P} 2$ receptors [8, 9, 32-36], whose activation results in elevations in $\left[\mathrm{Ca}^{2+}\right] \mathrm{i}$ astrocytes. Subsequently, it was demonstrated that these $\mathrm{Ca}^{2+}$ elevations could in turn stimulate the release of chemical transmitters from glial cells, which mediates a communication between astrocytes and even neurons (see other section). Cornell-Bell (1990) showed that glutamate can elicit $\left[\mathrm{Ca}^{2+}\right] \mathrm{i}$ not only in individual cells, but also intercellular waves of increased $\left[\mathrm{Ca}^{2+}\right] \mathrm{i}$ that are propagated from single cells to multiple neighboring cells [24]. Dani et al. (1992) showed that neuronal activity can directly initiate such a $\mathrm{Ca}^{2+}$ wave in astrocytes [37]. Other stimuli such as local mechanical or electrical stimulation were subsequently observed to initiate similar intercellular $\mathrm{Ca}^{2+}$ signaling in astrocytes. Mechanical stimulation with a micropipette reliably evokes spreading $\mathrm{Ca}^{2+}$ waves in astrocytes [38], and has been used extensively as a stimulus for the focal initiation of $\mathrm{Ca}^{2+}$ waves, allowing us to analyze their characteristic spatiotemporal features. To evoke $\mathrm{Ca}^{2+}$ wave, the mechanical stimulus need not be associated with cell damage, since repetitive stimulation of the same cell can evoke repetitive $\mathrm{Ca}^{2+}$ waves with recovery of the $\left[\mathrm{Ca}^{2+}\right] \mathrm{i}$ to baseline levels between stimuli and with no leakage of intracellular $\mathrm{Ca}^{2+}$ indicator dyes. For some years, such $\mathrm{Ca}^{2+}$ waves have been thought to propagate via gap junctions [39-42], through which the internal messenger inositol 1,4,5-trisphosphate $\left(\mathrm{InsP}_{3}\right)$ can be diffused to mobilize $\mathrm{Ca}^{2+}$ release $[42,43]$. Stimulating a single glial cell leads to the production of $\mathrm{InsP}_{3}$, triggering the release of $\mathrm{Ca}^{2+}$ from internal stores in the stimulated cell as well as in adjacent cells. More recently, experiments in culture have shown that $\mathrm{Ca}^{2+}$ waves can be propagated between astrocytes, even when the cells do not contact each other directly, and the extent and direction of the $\mathrm{Ca}^{2+}$ wave propagation are significantly influenced by movement of the extracellular medium [8, 44]. Subsequent publications have confirmed that astrocytes do not absolutely require functional gap junction coupling for the spreading of $\mathrm{Ca}^{2+}$ waves in astrocytes $[45,46]$. These more recent reports suggest that substances released from astrocytes can activate receptor systems on astrocytes, evoking the release of additional substances (either the same or different compounds), and thus producing a propagating $\mathrm{Ca}^{2+}$ wave of activity. Recently, it has been found that extracellular ATP is the major messenger for this event. First, ATP is released from astrocytes during $\mathrm{Ca}^{2+}$ wave propagation $[8,11]$. Second, the propagation can be reduced or abolished by a purinergic antagonist [8, $10-12,35,47]$ or the ATP degrading enzyme apyrase [8, $47,48]$. In addition, visualization of the release of ATP demonstrated that the velocity of ATP release well correlates with that of the $\mathrm{Ca}^{2+}$ wave in astrocytes [47]. All these findings suggest that the extracellular molecule ATP could be a primary signal for the $\mathrm{Ca}^{2+}$ wave propagation, and highlight the importance of ATP in cross-talk among astrocytes and even other cell types in the CNS.

So far, the physiological consequences of the ATPevoked increase in $\left[\mathrm{Ca}^{2+}\right] \mathrm{i}$ in astrocytes themselves have received only limited attention. Stimulation of astrocytes with ATP enhances mitogenic signaling via the ERKmediated pathway, increases proliferation [49, 50], and protects astrocytes against oxidative stress [51]. Further comprehensive studies will reveal the importance of ATPmediated $\mathrm{Ca}^{2+}$ responses in astrocytes.

\section{Astrocyte-to-microglia communication}

Intercellular $\mathrm{Ca}^{2+}$ waves in astrocytes also trigger microglial $\mathrm{Ca}^{2+}$ responses in a manner dependent on extracellu- 
lar ATP. As described above, astrocytes release ATP upon mechanical stimulation [8], electrical stimulation [8] or glutamatergic receptor activation [52], and respond to locally applied ATP with a propagating $\mathrm{Ca}^{2+}$ wave. Microglia have been shown to express functionally active P2 receptors in culture and in situ [53-60], suggesting the possibility that ATP could also mediate astrocyte-tomicroglia communication. In fact, Verderio and Matteoli demonstrated that mechanical and bradykinin stimulation resulted in the release of ATP from astrocytes, which, in turn triggered delayed $\mathrm{Ca}^{2+}$ responses in adjacent microglia via P2X7 receptors in a mixed culture of astrocytes and microglia [61]. Schipke et al. showed that electrical stimulation of astrocytes produced $\mathrm{Ca}^{2+}$ waves that triggered $\mathrm{Ca}^{2+}$ responses in microglia in an extracellular ATPdependent manner in a slice preparation of mouse. Thus, it appears that extracellular ATP-dependent $\mathrm{Ca}^{2+}$ waves could occur in situ and are not restricted to astrocytes but broadly activate different glial cell types. The astrocytic ATP-mediated intercellular communication was also observed in meningeal cells [62] and Muller cells [35]. Recently, Tsuda et al. have reported that the expression of $\mathrm{P} 2 \mathrm{X}_{4}$ receptors in the spinal cord is enhanced in spinal microglia after peripheral nerve injury, and that blocking pharmacologically and suppressing molecularly $\mathrm{P} 2 \mathrm{X}_{4}$ receptors cause a reduction of the neuropathic pain behavior $[55,63]$. Thus, P2-receptor mediated microglial $\mathrm{Ca}^{2+}$ excitability may be of great consequence for pathological events such as chronic pain. In addition, peripheral sensory axons release ATP that activates P2 receptors in neighboring Schwann cells, leading to the spreading of $\mathrm{Ca}^{2+}$ waves in the cells and regulation of their proliferation/differentiation [13]. It seems that extracellular ATP may function as a ubiquitous autocrine/paracrine in central and peripheral tissues.

\section{Mechanisms of ATP release from astrocytes}

Although several excitable and non-excitable cells release ATP, the mechanism underlying the release of ATP is controversial, especially in non-excitable cells such as astrocytes. With regard to glutamate release from astrocytes, recently some important findings have been reported. Astrocytes express SNARE proteins [64-67], have a vesicular structure expressing the vesicular glutamate transporters $[65,66]$, and the release of glutamate is dependent on $\mathrm{Ca}^{2+}[68,69]$, sensitive to SNAREs $[65,67$, 70]. These findings strongly suggest that exocytotic machinery is involved in glutamate release in astrocytes although non-vesicular mechanisms for glutamate release are also proposed [71-74]. In contrast, mechanisms underlying the release of ATP from astrocytes are still a matter of debate. The release of ATP is reduced by inhibitors for several anion channels [75, 76], ATP binding cassette proteins or CFTR [77-81], gap junction [10, 82], suggesting the involvement of multiple pathways for the release. In addition, the release of ATP is partly dependent on $\mathrm{Ca}^{2+}[10,79,83]$, and SNARE proteins $[84,85]$, and astrocytes seem to possess vesicles that contain ATP inside $[84,86]$. Inhibition of ATP release by vesicular ATPase inhibitors was also reported [86]. These findings suggest that the mechanisms of ATP release could include exocytosis. Furthermore, the nature of the signals released from astrocytes may differ under varying physiological and pathological conditions [86]. Exocytotic mechanisms for ATP have been reported in other non-excitable cells. For example, in vascular endothelial cells, the shear stressevoked ATP release is vesicular and dependent on $\mathrm{Ca}^{2+}$ [87]. It would be very important to elucidate the mechanisms by which astrocytes release ATP in response to distinct stimuli, which would further establish the position of astrocytes as an important partner of neurons in forming the "tripartite synapse" [88].

\section{Astrocyte-to-neuron communication}

As described above, astrocytes lack the ability to propagate regenerative electrical signals but are nonetheless responsive to a variety of extracellular stimuli and produce regenerative $\mathrm{Ca}^{2+}$ waves that spread within astrocyte networks $[8,12,35,47] . \mathrm{Ca}^{2+}$ excitability in astrocytes can evoke the release of neuroactive substances such as glutamate and ATP.

Glutamate is the predominant signaling molecule among the previously reported mechanisms through which astrocytes can actively regulate synaptic transmission. In cultured hippocampal neurons, the stimulation of astrocytes evokes a regenerative, $\mathrm{Ca}^{2+}$-dependent release of glutamate from astrocytes which, in turn, can enhance excitatory synaptic transmission via $N$-methyl-D-aspartate receptor-mediated mechanisms [6]. Glutamate-mediated astrocyte-to-neuron signaling has also been observed in hippocampal slices [89-91], visual cortical slices [3] and in the retina [7], although the subclass of responsible glutamate receptors varied among the different preparations. However, astrocytic ATP has recently been shown to decrease the excitability of neurons in the retina [92], and mediate presynaptic inhibition in cultured hippocampal neurons $[47,93]$. Cultured hippocampal neurons reveal synchronous spontaneous $\mathrm{Ca}^{2+}$ oscillation, which is extracellular $\mathrm{Ca}^{2+}$-dependent, tetrodotoxin-sensitive and inhibited by inhibitors of ionotropic glutamate receptors, suggesting that the neuronal $\mathrm{Ca}^{2+}$ oscillation is mediated by glutamatergic synaptic transmission [20, 47, 94, 95]. Endogenous ATP released from astrocytes dynamically downregulates the spontaneous neuronal $\mathrm{Ca}^{2+}$ oscillation [47] and EPSCs in the hippocampal culture [93] by inhibiting presynaptic functions of glutamatergic neurons. Similar astrocytic ATP-mediated presynaptic inhibition was observed in the hippocampus in situ [93] although adenosine, a metabolite of ATP degraded by ecto-nucleotidases, also functioned as an inhibitory molecule in the slices. ATP would differ from glutamate as a signaling molecule between astrocytes and neurons in that it inhibits rather than potentiates synaptic 
transmission. We hypothesize that the opposing actions of glutamate and ATP released from astrocytes represent a means by which astrocytes can dynamically modulate neuronal activity by releasing distinct transmitters which can either excite or inhibit synaptic transmission. Very recently, Bowser and Khakh (2004) have demonstrated that electrical stimulation of Schaffer collaterals and perforant path in hippocampal slices evoked both an increase in $\left[\mathrm{Ca}^{2+}\right] \mathrm{i}$ in astrocytes and facilitation of GABAergic IPSCs onto interneurons in the CA1 stratum radiatum [96], both of which were mediated by $\mathrm{P} 2 \mathrm{Y} 1$ receptors. Similar responses were observed in the $\mathrm{CA} 3$ region of the hippocampus [97]. Endogenously released ATP from neurons and astrocytes can activate $\mathrm{P} 2 \mathrm{Y} 1$ receptors on astrocytes and postsynaptic interneurons to activate $\left[\mathrm{Ca}^{2+}\right] \mathrm{i}$ elevations and facilitation of synaptic inhibition, respectively. This might be another form of astrocyte-to-neuron communication in the hippocampus because astrocytes may release and propagate a wave of ATP, which activates P2Y1 receptors on postsynaptic GABAergic interneurons, leading to increased synaptic inhibition in interneuron networks in situ $[96,97]$.

In addition to mediating inhibitory rather than excitatory effects on synaptic transmission, ATP-mediated astrocyteto-neuron signaling further differs from glutamate-dependent signaling mechanisms by the fact that it occurs in a tonic fashion [47, 93]. Application of the ATP-degrading enzyme apyrase induces a potentiation of spontaneous neuronal $\mathrm{Ca}^{2+}$ oscillations or EPSCs in the absence of any astrocytic stimulation, suggesting the presence of a constitutive ATP-dependent inhibition of synaptic transmission. Furthermore, spontaneous astrocytic $\mathrm{Ca}^{2+}$ responses occur in both purified astrocyte cultures and mixed cultures of astrocytes and neurons. The spontaneous $\mathrm{Ca}^{2+}$ signals in astrocytes were inhibited by apyrase but persisted in the presence of TTX. Therefore, astrocytes constitutively release ATP in the absence of neuronal activity, which exerts tonic down-regulation of excitatory synaptic transmission $[47,93]$. ATP mediates astrocytic $\mathrm{Ca}^{2+}$ waves and can evoke neuronal $\mathrm{Ca}^{2+}$ responses in various parts of the CNS such as the habenula [14], suggesting that ATP may be an ubiquitous mediator of astrocyte-to-neuron signaling in the modulation of synaptic activity. Such a tonic modulation by astrocytic ATP might be a mechanism by which neurons tune their communications in the CNS.

The ATP receptor subtype(s) implicated in the ATPmediated inhibition of presynaptic transmission in hippocampal neurons remains unknown [47, 93]. Although apyrase abolished the ATP-mediated inhibition, the nonselective P2 receptor antagonists suramin and PPADS were only able to partially attenuate the effects of exogenously applied ATP [20]. Similarly, these antagonists only slightly affected the decrease in neuronal $\mathrm{Ca}^{2+}$ oscillations evoked by mechanical stimulation of an astrocyte [47] but reactive blue 2 reduced the effect of ATP [93]. Thus, involvement of $\mathrm{P} 2 \mathrm{Y}$ receptors in the inhibitory action was suggested [93] although reactive blue 2 could also affect $\mathrm{P} 2 \mathrm{X}$ receptors. Adenosine, a metabolite of ATP, is also involved in the inhibitory action via adenosine A1 receptors [20, 21,
98]. Released ATP might exhibit its inhibitory action by being metabolized into adenosine. However, the ATPevoked inhibition did not disappear even in the presence of several antagonists to adenosine receptors, A1 receptors or adenosine deaminase in hippocampal neurons [20, 99, 100]. In addition, the effect of astrocytic ATP on the synaptic transmission almost disappeared in the presence of apyrase (grade III), which degrades ATP and ADP into ADP and AMP, respectively but does not affect the metabolism of adenosine [20, 47]. All these findings suggest that ATP itself is involved in the inhibition of synaptic transmission, but we cannot identify the responsible receptor subclasses so far. Recently, the oligomeric association of $\mathrm{A} 1$ receptors with $\mathrm{P} 2 \mathrm{Y} 1$ receptors (A1/P2Y1 receptors) generating $\mathrm{A} 1$ with $\mathrm{P} 2 \mathrm{Y} 1$ receptor-like agonistic pharmacology has been reported [101, 102]. Such an oligomeric association occurs in hippocampal neurons [103] and the pharmacological characteristics of A1/P2Y1 receptors are similar to those involved in the inhibition of neuronal $\mathrm{Ca}^{2+}$ oscillations [20]. However, the discovery of specific antagonists for such oligomeric A1/P2Y1 receptors is required to determine if they are involved in ATPmediated inhibition of neuronal activity.

\section{Conclusion}

Astrocytes release ATP, glutamate or other active substances in response to various stimuli or even spontaneously, by which the activities of adjacent astrocytes or even neurons are positively and dynamically controlled (Figure 1). Now we know that rapid neurotransmission is not restricted solely to neuron-to-neuron communication but also includes glial cells. Especially, astrocytes can receive neurotransmitters, respond to them, and send output signals to neighboring neurons, forming a so-called "tripartite synapse". For this, extracellular ATP and P2 receptors appear to have a central role. Further extensive

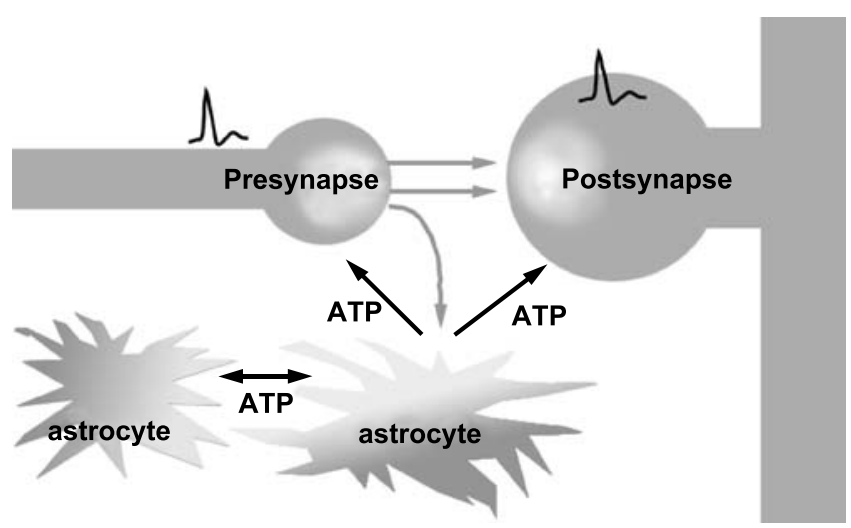

Figure 1. A schematic diagram of "tripartite synapse" mediated by extracellular ATP neurotransmitters, spilling over from the synapse, stimulate surrounding astrocytes (gray arrows). Astrocytes have a big variety of neurotransmitter receptors, and can release diffusible molecules such as ATP in response to the neurotransmitters, and form propagating $\mathrm{Ca}^{2+}$ waves in astrocytes. Astrocytic ATP has an essential role for the formation of the intercellular $\mathrm{Ca}^{2+}$ wave, and in turn functions as a feedback signal to modulate synaptic transmission in adjacent neurons. 
studies will be required to clarify the physiological or pathological significance of astrocytes in synaptic transmission, the mechanisms underlying the release of ATP from astrocytes and the distinct functions of glutamate and ATP as gliotransmitters. At present, it may be thought that glial cells play a subordinate role in the brain function, especially in the processing and integration of information. However, the glial era has just started, and exciting discoveries can be expected. Being partner with ATP, astrocyte can be a star.

\section{Acknowledgements}

We thank Tomoko Obama for technical assistance, Yasuo Ohno for continuous encouragement. This work was partly supported by The Pharmaceuticals and Medical Device Agency (MF-16), The Japan Health Science Foundation, The Brain Science Foundation, The Naito Foundation and the Grant-in-Aid for Scientific Research.

\section{References}

1. Haydon PG. GLIA: Listening and talking to the synapse. Nat Rev Neurosci 2001; 2: 185-93.

2. Ransom B, Behar T, Nedergaard M. New roles for astrocytes (stars at last). Trends Neurosci 2003; 26: 520-2.

3. Nedergaard M. Direct signaling from astrocytes to neurons in cultures of mammalian brain cells. Science 1994; 263: 1768-71.

4. Bezzi P, Carmignoto G, Pasti L et al. Prostaglandins stimulate calcium-dependent glutamate release in astrocytes. Nature 1998; 391: 281-5.

5. Pasti L, Volterra A, Pozzan $\mathrm{T}$ et al. Intracellular calcium oscillations in astrocytes: A highly plastic, bidirectional form of communication between neurons and astrocytes in situ. J Neurosci 1997; 17: 7817-30.

6. Araque A, Parpura V, Sanzgiri RP et al. Glutamate-dependent astrocyte modulation of synaptic transmission between cultured hippocampal neurons. Eur J Neurosci 1998; 10: 2129-42.

7. Newman EA, Zahs KR. Modulation of neuronal activity by glia cells in the retina. J Neurosci 1998; 18: 4022-8.

8. Guthrie PB, Knappenberger J, Segal M et al. ATP released from astrocytes mediates glial calcium waves. J Neurosci 1999; 19 520-8.

9. Salter MW, Hicks JL. ATP-evoked increases in intracellular calcium in neurons and glia from the dorsal spinal cord. J Neurosci 1994; 14: 1563-75.

10. Cotrina ML, Lin JH, Alves-Rodrigues A et al. Connexins regulate calcium signaling by controlling ATP release. Proc Natl Acad Sci USA 1998; 95: 15735-40.

11. Cotrina ML, Lin JH, Lopez-Garcia JC et al. ATP-mediated glia signaling. J Neurosci 2000; 20: 2835-44.

12. Fam SR, Gallagher CJ, Salter MW. P2Y(1) purinoceptor-mediated $\mathrm{Ca}(2+)$ signaling and $\mathrm{Ca}(2+)$ wave propagation in dorsal spinal cord astrocytes. J Neurosci 2000; 20: 2800-8.

13. Stevens B, Fields RD. Response of Schwann cells to action potentials in development. Science 2000; 287: 2267-71.

14. Edwards FA, Gibb AJ, Colquhoun D. ATP receptor-mediated synaptic currents in the central nervous system. Nature 1992; 359: 144-7.

15. Bardoni R, Goldstein PA, Lee CJ et al. ATP P2X receptors mediate fast synaptic transmission in the dorsal horn of the rat spinal cord. J Neurosci 1997; 17: 5297-304.
16. Hugel S, Schlichter R. Presynaptic P2X receptors facilitate inhibitory GABAergic transmission between cultured rat spinal cord dorsal horn neurons. J Neurosci 2000; 20: 2121-30.

17. $\mathrm{Gu} \mathrm{JG}$, MacDermott AB. Activation of ATP P2X receptors elicits glutamate release from sensory neuron synapses. Nature 1997; 389: 749-53.

18. Kato F, Shigetomi E. Distinct modulation of evoked and spontaneous EPSCs by purinoceptors in the nucleus tractus solitarii of the rat. J Physiol 2001; 530: 469-86.

19. Shigetomi E, Kato F. Action potential-independent release of glutamate by $\mathrm{Ca}^{2+}$ entry through presynaptic $\mathrm{P} 2 \mathrm{X}$ receptors elicits postsynaptic firing in the brainstem autonomic network. J Neurosci 2004; 24: 3125-35.

20. Koizumi S, Inoue K. Inhibition by ATP of calcium oscillations in rat cultured hippocampal neurones. Br J Pharmacol 1997; 122: 51-8.

21. Cunha RA, Ribeiro JA. ATP as a presynaptic modulator. Life Sci 2000; 68: 119-37.

22. Enkvist MO, Holopainen I, Akerman KE. Alpha-receptor and cholinergic receptor-linked changes in cytosolic $\mathrm{Ca}^{2+}$ and membrane potential in primary rat astrocytes. Brain Res 1989; 500: 46-54.

23. Enkvist MO, Holopainen I, Akerman KE. Glutamate receptorlinked changes in membrane potential and intracellular $\mathrm{Ca}^{2+}$ in primary rat astrocytes. Glia 1989; 2: 397-402.

24. Cornell-Bell AH, Finkbeiner SM, Cooper MS et al. Glutamate induces calcium waves in cultured astrocytes: Long-range glial signaling. Science 1990; 247: 470-3.

25. Parpura V, Haydon PG. Physiological astrocytic calcium levels stimulate glutamate release to modulate adjacent neurons. Proc Natl Acad Sci USA 2000; 97: 8629-34.

26. Khan ZU, Koulen $P$, Rubinstein $M$ et al. An astroglia-linked dopamine D2-receptor action in prefrontal cortex. Proc Natl Acad Sci USA 2001; 98: 1964-9.

27. Mulligan SJ, MacVicar BA. Calcium transients in astrocyte endfeet cause cerebrovascular constrictions. Nature 2004; 431: 195-9.

28. Jalonen TO, Margraf RR, Wielt DB et al. Serotonin induces inward potassium and calcium currents in rat cortical astrocytes. Brain Res 1997; 758: 69-82.

29. Thorlin T, Eriksson PS, Ronnback L et al. Receptor-activated $\mathrm{Ca}^{2+}$ increases in vibrodissociated cortical astrocytes: A nonenzymatic method for acute isolation of astrocytes. J Neurosci Res 1998; 54: $390-401$.

30. Blomstrand F, Khatibi S, Muyderman H et al. 5-Hydroxytryptamine and glutamate modulate velocity and extent of intercellular calcium signalling in hippocampal astroglial cells in primary cultures. Neuroscience 1999; 88: 1241-53.

31. Sanden N, Thorlin T, Blomstrand F et al. 5-Hydroxytryptamine2B receptors stimulate $\mathrm{Ca}^{2+}$ increases in cultured astrocytes from three different brain regions. Neurochem Int 2000; 36: 427-34.

32. Salter MW, Hicks JL. ATP causes release of intracellular $\mathrm{Ca}^{2+}$ via the phospholipase $\mathrm{C}$ beta/IP3 pathway in astrocytes from the dorsal spinal cord. J Neurosci 1995; 15: 2961-71.

33. Fumagalli M, Brambilla R, D'Ambrosi $\mathrm{N}$ et al. Nucleotidemediated calcium signaling in rat cortical astrocytes: Role of P2X and P2Y receptors. Glia 2003; 43: 203-18.

34. Neary JT, Kang Y Bu Y, et al. Mitogenic signaling by ATP/P2Y purinergic receptors in astrocytes: Involvement of a calciumindependent protein kinase $\mathrm{C}$, extracellular signal-regulated protein kinase pathway distinct from the phosphatidylinositol-specific phospholipase C/calcium pathway. J Neurosci 1999; 19: 4211-20.

35. Newman E A. Propagation of intercellular calcium waves in retinal astrocytes and Muller cells. J Neurosci 2001; 21: 2215-23.

36. Koizumi S, Saito Y, Nakazawa K et al. Spatial and temporal aspects of $\mathrm{Ca}^{2+}$ signaling mediated by $\mathrm{P} 2 \mathrm{Y}$ receptors in cultured rat hippocampal astrocytes. Life Sci 2002; 72: 431-42.

37. Dani JW, Chernjavsky A, Smith SJ. Neuronal activity triggers calcium waves in hippocampal astrocyte networks. Neuron 1992; 8: 429-40. 
38. Charles AC, Merrill JE, Dirksen ER et al. Intercellular signaling in glial cells: Calcium waves and oscillations in response to mechanical stimulation and glutamate. Neuron 1991; 6: 983-92.

39. Boitano S, Dirksen ER, Sanderson MJ. Intercellular propagation of calcium waves mediated by inositol trisphosphate. Science 1992; 258: 292-5.

40. Charles AC, Dirksen ER, Merrill JE et al. Mechanisms of intercellular calcium signaling in glial cells studied with dantrolene and thapsigargin. Glia 1993; 7: 134-45.

41. Sneyd J, Charles AC, Sanderson MJ. A model for the propagation of intercellular calcium waves. Am J Physiol 1994; 266 : C293-302.

42. Sneyd J, Wetton BT, Charles AC et al. Intercellular calcium waves mediated by diffusion of inositol trisphosphate: A two-dimensional model. Am J Physiol 1995; 268: C1537-45.

43. Sanderson MJ, Charles AC, Boitano S et al. Mechanisms and function of intercellular calcium signaling. Mol Cell Endocrinol 1994; 98: 173-87.

44. Hassinger TD, Guthrie PB, Atkinson PB et al. An extracellular signaling component in propagation of astrocytic calcium waves. Proc Natl Acad Sci USA 1996; 93: 13268-73.

45. Guan X, Cravatt BF, Ehring GR et al. The sleep-inducing lipid oleamide deconvolutes gap junction communication and calcium wave transmission in glial cells. J Cell Biol 1997; 139: 1785-92.

46. Naus CC, Bechberger JF, Zhang Y et al. Altered gap junctional communication, intercellular signaling, and growth in cultured astrocytes deficient in connexin43. J Neurosci Res 1997; 49: 528-40.

47. Koizumi S, Fujishita K, Tsuda M et al. Dynamic inhibition of excitatory synaptic transmission by astrocyte-derived ATP in hippocampal cultures. Proc Natl Acad Sci USA 2003; 100: 11023-8.

48. John GR, Scemes E, Suadicani SO et al. IL-1beta differentially regulates calcium wave propagation between primary human fetal astrocytes via pathways involving P2 receptors and gap junction channels. Proc Natl Acad Sci USA 1999; 96: 11613-8.

49. Abbracchio MP, Saffrey MJ, Hopker V et al. Modulation of astroglial cell proliferation by analogues of adenosine and ATP in primary cultures of rat striatum. Neuroscience 1994; 59: 67-76.

50. Bolego C, Ceruti S, Brambilla $\mathrm{R}$ et al. Characterization of the signalling pathways involved in ATP and basic fibroblast growth factor-induced astrogliosis. Br J Pharmacol 1997; 121: 1692-9.

51. Shinozaki Y, Koizumi S, Ishida S et al. Cytoprotection against oxidative stress-induced damage of astrocytes by extracellular ATP via P2Y(1) receptors. Glia 2004; 49: 288-300.

52. Queiroz G, Gebicke-Haerter PJ, Schobert A et al. Release of ATP from cultured rat astrocytes elicited by glutamate receptor activation. Neuroscience 1997; 78: 1203-8.

53. Honda S, Sasaki Y, Ohsawa K et al. Extracellular ATP or ADP induce chemotaxis of cultured microglia through Gi/o-coupled P2Y receptors. J Neurosci 2001; 21: 1975-82.

54. Shigemoto-Mogami Y, Koizumi S, Tsuda M et al. Mechanisms underlying extracellular ATP-evoked interleukin-6 release in mouse microglial cell line, MG-5. J Neurochem 2001; 78: 1339-49.

55. Tsuda M, Shigemoto-Mogami Y, Koizumi S et al. P2X4 receptors induced in spinal microglia gate tactile allodynia after nerve injury. Nature 2003; 424: 778-83.

56. Suzuki T, Hide I, Ido $\mathrm{K}$ et al. Production and release of neuroprotective tumor necrosis factor by $\mathrm{P} 2 \mathrm{X} 7$ receptor-activated microglia. J Neurosci 2004; 24: 1-7.

57. Ferrari D, Villalba M, Chiozzi $\mathrm{P}$ et al. Mouse microglial cells express a plasma membrane pore gated by extracellular ATP. J Immunol 1996; 156: 1531-9.

58. Norenberg W, Cordes A, Blohbaum G et al. Coexistence of purinoand pyrimidinoceptors on activated rat microglial cells. $\mathrm{Br} \mathrm{J}$ Pharmacol 1997; 121: 1087-98.

59. Moller T, Kann O, Verkhratsky A et al. Activation of mouse microglial cells affects P2 receptor signaling. Brain Res 2000; 853: 49-59.

60. Boucsein C, Zacharias R, Farber K et al. Purinergic receptors on microglial cells: Functional expression in acute brain slices and modulation of microglial activation in vitro. Eur J Neurosci 2003; 17: 2267-76.

61. Verderio C, Matteoli M. ATP mediates calcium signaling between astrocytes and microglial cells: Modulation by IFN-gamma. J Immunol 2001; 166: 6383-91.

62. Grafstein B, Liu S, Cotrina ML et al. Meningeal cells can communicate with astrocytes by calcium signaling. Ann Neurol 2000; 47: 18-25.

63. Tsuda M, Mizokoshi A, Shigemoto-Mogami Y et al. Activation of p38 mitogen-activated protein kinase in spinal hyperactive microglia contributes to pain hypersensitivity following peripheral nerve injury. Glia 2004; 45: 89-95.

64. Hepp R, Perraut M, Chasserot-Golaz S et al. Cultured glial cells express the SNAP-25 analogue SNAP-23. Glia 1999; 27: 181-7.

65. Bezzi P, Gundersen V, Galbete JL et al. Astrocytes contain a vesicular compartment that is competent for regulated exocytosis of glutamate. Nat Neurosci 2004; 7: 613-20.

66. Wilhelm A, Volknandt W, Langer D et al. Localization of SNARE proteins and secretory organelle proteins in astrocytes in vitro and in situ. Neurosci Res 2004; 48: 249-57.

67. Zhang Q, Fukuda M, Van Bockstaele E et al. Synaptotagmin IV regulates glial glutamate release. Proc Natl Acad Sci USA 2004; 101: 9441-6.

68. Kreft M, Stenovec M, Rupnik M et al. Properties of $\mathrm{Ca}(2+)$ dependent exocytosis in cultured astrocytes. Glia 2004; 46: 437-45.

69. Zhang Q, Pangrsic T, Kreft $M$ et al. Fusion-related release of glutamate from astrocytes. J Biol Chem 2004; 279: 12724-33.

70. Araque A, Li N, Doyle RT et al. SNARE protein-dependent glutamate release from astrocytes. J Neurosci 2000; 20: 666-73.

71. Nicholls D, Attwell D. The release and uptake of excitatory amino acids. Trends Pharmacol Sci 1990; 11: 462-8.

72. Kimelberg HK, Goderie SK, Higman S et al. Swelling-induced release of glutamate, aspartate, and taurine from astrocyte cultures. J Neurosci 1990; 10: 1583-91.

73. Jabaudon D, Shimamoto K, Yasuda-Kamatani $\mathrm{Y}$ et al. Inhibition of uptake unmasks rapid extracellular turnover of glutamate of nonvesicular origin. Proc Natl Acad Sci USA 1999; 96: 8733-8.

74. Duan S, Anderson CM, Keung EC et al. P2X7 receptor-mediated release of excitatory amino acids from astrocytes. J Neurosci 2003; 23: $1320-8$.

75. Anderson CM, Bergher JP, Swanson RA. ATP-induced ATP release from astrocytes. J Neurochem 2004; 88: 246-56.

76. Darby M, Kuzmiski JB, Panenka W, et al. ATP released from astrocytes during swelling activates chloride channels. J Neurophysiol 2003; 89: 1870-7.

77. Abraham EH, Prat AG, Gerweck L et al. The multidrug resistance (mdr1) gene product functions as an ATP channel. Proc Natl Acad Sci USA 1993; 90: 312-6.

78. Reisin IL, Prat AG, Abraham EH et al. The cystic fibrosis transmembrane conductance regulator is a dual ATP and chloride channel. J Biol Chem 1994; 269: 20584-91.

79. Queiroz G, Meyer DK, Meyer A, et al. A study of the mechanism of the release of ATP from rat cortical astroglial cells evoked by activation of glutamate receptors. Neuroscience 1999; 91: 1171-81.

80. Ballerini P, Di Iorio P, Ciccarelli R et al. Glial cells express multiple ATP binding cassette proteins which are involved in ATP release. NeuroReport 2002; 13: 1789-92.

81. Bodin P, Burnstock G. Purinergic signalling: ATP release. Neurochem Res 2001; 26: 959-69.

82. Stout CE, Costantin JL, Naus CC et al. Intercellular calcium signaling in astrocytes via ATP release through connexin hemichannels. J Biol Chem 2002; 277: 10482-8.

83. Bal-Price A, Moneer Z, Brown GC. Nitric oxide induces rapid, calcium-dependent release of vesicular glutamate and ATP from cultured rat astrocytes. Glia 2002; 40: 312-23.

84. Maienschein V, Marxen M, Volknandt W et al. A plethora of presynaptic proteins associated with ATP-storing organelles in cultured astrocytes. Glia 1999; 26: 233-44. 
85. Abdipranoto A, Liu G J, Werry EL et al. Mechanisms of secretion of ATP from cortical astrocytes triggered by uridine triphosphate. NeuroReport 2003; 14: 2177-81.

86. Coco S, Calegari F, Pravettoni E et al. Storage and release of ATP from astrocytes in culture. J Biol Chem 2003; 278: 1354-62.

87. Bodin P, Burnstock G. Evidence that release of adenosine triphosphate from endothelial cells during increased shear stress is vesicular. J Cardiovasc Pharmacol 2001; 38: 900-8.

88. Araque A, Parpura V, Sanzgiri RP et al. Tripartite synapses: Glia, the unacknowledged partner. Trends Neurosci 1999; 22: 208-15.

89. Kang J, Jiang L, Goldman SA et al. Astrocyte-mediated potentiation of inhibitory synaptic transmission. Nat Neurosci 1998; 1: 683-92.

90. Fellin T, Pascual O, Gobbo S et al. Neuronal synchrony mediated by astrocytic glutamate through activation of extrasynaptic NMDA receptors. Neuron 2004; 43: 729-43.

91. Fiacco TA, McCarthy KD. Intracellular astrocyte calcium waves in situ increase the frequency of spontaneous AMPA receptor currents in CA1 pyramidal neurons. J Neurosci 2004; 24: 722-32.

92. Newman EA. Glial cell inhibition of neurons by release of ATP. J Neurosci 2003; 23: 1659-66.

93. Zhang JM, Wang HK, Ye CQ et al. ATP released by astrocytes mediates glutamatergic activity-dependent heterosynaptic suppression. Neuron 2003; 40: 971-82.

94. Ogura A, Iijima T, Amano T et al. Optical monitoring of excitatory synaptic activity between cultured hippocampal neurons by a multisite $\mathrm{Ca}^{2+}$ fluorometry. Neurosci Lett 1987; 78: 69-74.

95. Bacci A, Verderio C, Pravettoni E et al. Synaptic and intrinsic mechanisms shape synchronous oscillations in hippocampal neurons in culture. Eur J Neurosci 1999; 11: 389-97.

96. Bowser DN, Khakh BS. ATP excites interneurons and astrocytes to increase synaptic inhibition in neuronal networks. J Neurosci 2004; 24: 8606-20.

97. Kawamura M, Gachet $\mathrm{C}$, Inoue $\mathrm{K}$ et al. Direct excitation of inhibitory interneurons by extracellular ATP mediated by P2Y1 receptors in the hippocampal slice. J Neurosci 2004; 24: 10835-45.

98. Cunha RA, Sebastiao AM, Ribeiro JA. Inhibition by ATP of hippocampal synaptic transmission requires localized extracellular catabolism by ecto-nucleotidases into adenosine and channeling to adenosine A1 receptors. J Neurosci 1998; 18: 1987-95.

99. Koch H, Kugelgen I, Starke K. P2-receptor-mediated inhibition of noradrenaline release in the rat hippocampus. Naunyn Schmiedebergs Arch Pharmacol 1997; 355: 707-15.

100. Mendoza-Fernandez V, Andrew RD, Barajas-Lopez C. ATP inhibits glutamate synaptic release by acting at $\mathrm{P} 2 \mathrm{Y}$ receptors in pyramidal neurons of hippocampal slices. J Pharmacol Exp Ther 2000; 293: 172-9.

101. Yoshioka K, Saitoh O, Nakata H. Heteromeric association creates a P2Y-like adenosine receptor. Proc Natl Acad Sci USA 2001; 98: 7617-22.

102. Yoshioka K, Nakata H. ATP- and adenosine-mediated signaling in the central nervous system: purinergic receptor complex: generating adenine nucleotide-sensitive adenosine receptors. J Pharmacol Sci 2004; 94: 88-94.

103. Yoshioka K, Hosoda R, Kuroda Y et al. Hetero-oligomerization of adenosine A1 receptors with $\mathrm{P} 2 \mathrm{Y} 1$ receptors in rat brains. FEBS Lett 2002; 531: 299-303. 